\title{
Phenotypic plasticity in the foot size of an intertidal snail
}

GC Trussell

Virginia Institute of Marine Science

Follow this and additional works at: https://scholarworks.wm.edu/vimsarticles

Part of the Marine Biology Commons

\section{Recommended Citation}

Trussell, GC, "Phenotypic plasticity in the foot size of an intertidal snail" (1997). VIMS Articles. 1739. https://scholarworks.wm.edu/vimsarticles/1739 


\title{
PHENOTYPIC PLASTICITY IN THE FOOT SIZE OF AN INTERTIDAL SNAIL
}

\author{
Geoffrey C. Trussell ${ }^{1}$ \\ Department of Zoology, University of New Hampshire, Durham, New Hampshire 03824, and \\ School of Marine Science, Virginia Institute of Marine Science, College of William and Mary,
} Gloucester Point, Virginia 23062

\begin{abstract}
The risk of dislodgment due to hydrodynamic forces on rocky intertidal shores is greater on wave-exposed than on protected shores, and this is believed to represent an important selective force in intertidal communities. For intertidal snails, the probability of dislodgment by a given flow is determined, in part, by shell size and shape, and by the attachment strength of the foot. This study addressed two questions. First, do habitat-specific differences in traits that reduce the risk of dislodgment of an intertidal snail (Littorina obtusata) parallel differences in wave energies? To address this question, I measured variation in (1) shell size (defined as the maximum projected surface area, MPSA); (2) foot size; (3) maximum shear dislodgment force; and (4) tenacity (dislodgment force per unit foot size) of two wave-exposed and three protected snail populations. Second, are habitatspecific differences in foot size, and hence attachment strength, the product of selection or of phenotypic plasticity in response to increased hydrodynamic stress? I conducted field transplant experiments and a laboratory flume experiment that manipulated water velocity to test for plasticity in foot size.

Wave-exposed snails exhibited traits that reduce the risk of dislodgment. Their shells were smaller (MPSA) and more squat (shell height relative to MPSA and shell length) than were shells of protected conspecifics. Wave-exposed snails also had larger foot sizes and were thus able to resist greater shear dislodgment forces than protected conspecifics of similar MPSA. Neither wave exposure nor collection site influenced tenacity, indicating that the greater dislodgment forces of wave-exposed snails were due to their larger foot sizes. Assuming that MPSA is proportional to speed-specific drag, which is reasonable for bluff bodies, I found that dislodgment force was proportional to drag. Foot size scaled isometrically with MPSA, and dislodgment force scaled isometrically with foot size, indicating that the risk of dislodgment does not change as snails grow.

The field and laboratory flume experiments provide the first clear demonstration that increased hydrodynamic stress induces plastic increases in foot size. Protected snails raised on a wave-exposed shore produced a larger foot than controls raised on their native shore. Selection on the foot size of protected snails raised on both shores was not detected in either habitat. Protected snails also produced larger foot sizes when raised in high-velocity flumes relative to snails raised under low-velocity flow. In contrast, wave-exposed snails exhibited no change in foot size when raised under both high- and low-velocity flow. Hence, variation in the foot size of wave-exposed snails is less flexible than that of protected conspecifics. If natural selection favors plasticity in heterogeneous environments, an asymmetry may be favored as well, especially if there are risks associated with improper adjustments to unpredictable environmental cues.
\end{abstract}

Key words: biomechanics; dislodgment; drag; Littorina obtusata; natural selection; New England; phenotypic plasticity; shell shape; shell size.

\section{INTRODUCTION}

An important goal of evolutionary ecology is understanding how organisms adapt to heterogeneous environments. Correlations between phenotypic variation within conspecifics and environmental gradients are often regarded as adaptive (Kitching and Lockwood 1974, Etter 1988a, Trussell et al. 1993, Trussell 1996).

Manuscript received 4 December 1995; revised 10 August 1996; accepted 10 September 1996; final version received 11 October 1996.

${ }^{1}$ Address for correspondence: 222 Upland Road, Cambridge, Massachusetts 02140 USA.
Adaptive arguments are made after identifying the functional role of the phenotype in a particular environment and how it serves to improve survivorship, growth, or reproduction (Kitching et al. 1966, Williams 1966, Stearns 1989). Because selection acts on phenotypes (Endler 1986), we must determine how phenotypic variation is produced if we are to understand the ecology and evolution of organisms in heterogeneous environments.

In addition to canalization and genetic polymorphism, natural selection has favored the evolution of phenotypic plasticity as an adaptation to environmental variation (Bradshaw 1965, Levins 1968, Stearns 1989, 
1992). Phenotypic plasticity is the modification of a phenotype in response to particular cues in the environment. Phenotypic variation resulting from plasticity can be discrete (developmental conversion) or continuous (phenotypic modulation) (Smith-Gill 1983, Lively $1986 a, b$, Stearns 1989). Plasticity is expected to be favored in unpredictable environments, especially when it results in phenotypes adapted to local environmental conditions. The diverse examples of plasticity, including aquatic zooplankton (Dodson 1989), barnacles (Lively 1986a), marine bryozoans (Harvell 1984), plants (Bradshaw 1965), fish (Bronmark and Miner 1992), tadpoles (Newman 1988a, b), and rocky intertidal snails (Appleton and Palmer 1988, Etter 1988a, Trussell 1996), suggest it is an important adaptation to environmental heterogeneity.

Wave energy on rocky intertidal shores creates an extremely heterogeneous environment (Lewis 1964, Newell 1979). Water velocities can range from $<1 \mathrm{~m} / \mathrm{s}$ on protected shores to $5-10 \mathrm{~m} / \mathrm{s}$ or greater on wave exposed shores (Denny et al. 1985). Hence, snails on these shores experience considerable variation in their flow environment. Many studies on intertidal snails reveal that growth rates (Janson 1982, Brown and Quinn 1988), reproductive output (Etter 1989), and shell morphology and size (Kitching et al. 1966, Etter 1988a, Trussell et al. 1993) are influenced or at least correlated with differences in wave energy.

The influence of wave energy on the above traits may be mediated by the risk of dislodgment by waves. This risk is greater on wave-exposed than on protected shores because water velocities and accelerations are greater (Denny 1985, 1988, Denny et al. 1985, Denny and Gaines 1990). Because of hydrodynamic differences between these two habitats, variation in traits that influence the risk of dislodgment, such as adhesive ability or size, may parallel differences in wave energy. Snails on wave-exposed shores must reduce this risk because dislodgment can reduce foraging time (Denny et al. 1985, Judge 1988) or sweep snails into atypical habitats (e.g., the subtidal zone) having more diverse predator assemblages (Sebens 1981, Etter 1988a).

Changes in snail morphology along gradients in wave energy are well known. Snails on wave-exposed shores typically have small sized, thinner shells and a larger adhesive foot than protected conspecifics (Kitching et al. 1966, Etter 1988a, Trussell et al. 1993, Trussell 1996). Natural selection imposed by the hydrodynamic constraints on wave-exposed shores, and by crab predation and desiccation stress on protected shores, is often invoked to explain this pattern. The hydrodynamic constraint hypothesis is intuitively appealing, but there is little direct evidence supporting it (Denny 1987, 1991; but see Kitching et al. 1966). Recent work indicates that phenotypic plasticity in response to crab predators (Appleton and Palmer 1988, Trussell 1996) and wave energy (Etter 1988a) contrib- utes to morphological differentiation of rocky intertidal snail populations.

Since the risk of dislodgment is greatest on waveexposed shores, I predicted that wave-exposed snails would have traits that reduce this risk. To address this hypothesis, I measured the shell shape and size, foot size, and adhesive ability of five populations of the intertidal snail Littorina obtusata to determine whether habitat-specific (wave-exposed vs. protected) differences in these traits exist. Replication of study populations extends the work of previous studies (e.g., Kitching et al. 1966, Etter 1988a, Trussell et al. 1993) that only used one wave-exposed and one protected population for comparison. To determine whether habitat-specific differences in foot size reflect plastic responses to increased wave energy, I conducted transplant experiments in the field with snails from both wave-exposed and protected populations. Because other variables in the field (in addition to wave-induced flow velocities and accelerations) may influence foot size, I also raised snails in laboratory flumes having different flow velocities to test for plasticity in foot size.

\section{Materials And Methods}

Morphological variation: Wave-exposed vs. protected

Study organism. - Littorina obtusata is an herbivorous snail on rocky intertidal shores along a gradient in wave energies from well-protected to wave-exposed. In North America, this species ranges from New Jersey to Newfoundland and southern Labrador (Bequaert 1943). While most abundant at midshore, this species is found throughout intertidal shores below the splash zone (Watson and Norton 1987, Williams 1992). During high tide or moist conditions, L. obtusata feeds directly on several fucoid species (Fucus spiralis, F. vesiculosus, F. serratus, and Ascophyllum nodosum) and on the epiphytic microflora growing on them. This species utilizes direct development, and juvenile snails immediately begin a benthic existence after emerging from egg masses laid principally on fucoid algae. Crabs, especially Carcinus maenas, are major predators of L. obtusata on protected shores (Reimchen 1982, G. C. Trussell, personal observation).

Study sites and sampling.-I studied variation in shell size, foot size and adhesive ability of two waveexposed $(\mathrm{E} 1=$ East Point, Nahant, Massachusetts $\left[42^{\circ} 25^{\prime} 12^{\prime \prime} \mathrm{N}, 70^{\circ} 54^{\prime} 6^{\prime \prime} \mathrm{W}\right]$ and E2 = Pemaquid Point, Maine $\left[43^{\circ} 50^{\prime} 00^{\prime \prime} \mathrm{N}, 69^{\circ} 39^{\prime} 12^{\prime \prime} \mathrm{W}\right]$ ) and three protected $(\mathrm{P} 1=$ Canoe Beach Cove, Nahant, Massachusetts [42 $\left.25^{\prime} 42^{\prime \prime} \mathrm{N}, 70^{\circ} 55^{\prime} 48^{\prime \prime} \mathrm{W}\right], \mathrm{P} 2$ = South Harpswell,

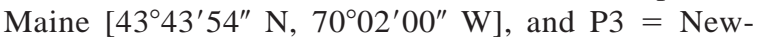
castle Island, New Hampshire [43 $04^{\prime} 20^{\prime \prime} \mathrm{N}, 70^{\circ} 42^{\prime} 30^{\prime \prime}$ W]) populations of Littorina obtusata in New England. East Point and Pemaquid Point project into the Gulf of Maine, and are two of the more wave-exposed sites in New England (Lubchenco and Menge 1978, Dudgeon 
and Johnson 1992). All three protected sites are blanketed by Ascophyllum nodosum, and are sheltered from the direct impact of breaking waves. During large storms from the northeast, the Canoe Beach Cove site can experience moderate wave energies (G. C. Trussell, personal observation). Snails were sampled from 0.25 $\mathrm{m}^{2}$ quadrats haphazardly tossed at the same tidal height $(\approx 1.5 \mathrm{~m} \mathrm{MLW}$ [mean low water]) on each shore in late September and early October 1991 . Three to five quadrats were tossed until I collected $\approx 50-75$ snails. Waveexposed snails were typically found in or near cracks and crevices, on Fucus distichus, or among beds of Chondrus crispus. Most protected snails collected were attached to $A$. nodosum, but a few individuals were found on bare rock beneath the A. nodosum canopy. Snails used for morphological and adhesive ability measurements were randomly sampled from the pool of individuals collected.

Hydrodynamic forces. - Hydrodynamic environments vary among shores, so variation in traits that reduce the risk of dislodgment may parallel gradients in waveexposure. Three hydrodynamic forces influence the risk of dislodgment of intertidal snails: (1) pressure drag (hereafter, drag), (2) acceleration reaction, and (3) lift (Denny et al. 1985). Drag acts in the direction of flow and is described by (Denny 1988),

$$
\text { Drag }=0.5 C_{\mathrm{d}} \rho S_{\mathrm{pr}} U^{2}
$$

where $C_{\mathrm{d}}=$ the coefficient of drag, a parameter that can be influenced by shape and Reynolds number (Re), $\rho=$ the density of seawater, $S_{\mathrm{pr}}=$ projected area of the shell normal to flow, and $U=$ water velocity.

Acceleration reaction results from changes in flow velocity and is described by (Denny 1988),

$$
\text { Acceleration Reaction }=\rho C_{\mathrm{m}} V a
$$

where $C_{\mathrm{m}}=$ the inertia coefficient, $V=$ the volume of the snail, and $a=$ the fluid's acceleration. Acceleration reaction always acts in the line of flow, but may not act in the same direction of flow (Denny 1988). Assuming that drag and acceleration reaction act in the same direction, the total shear force exerted on a snail in the direction of flow is described by the Morison equation (Morison et al. 1950),

$$
\text { Total Shear Force }=0.5 C_{\mathrm{d}} \rho S_{\mathrm{pr}} U^{2}+\rho C_{\mathrm{m}} V a
$$

which assumes that drag and acceleration reaction act independently and can thus be added (Denny 1988). Here I assume that both forces act in the direction of flow and impose a shear force on the foot.

Both drag and acceleration reaction impose shear forces on the foot of intertidal snails, but the magnitude of drag is expected to be substantially greater. Acceleration reaction is not expected to be important to the risk of dislodgment of smaller organisms like Littorina obtusata (Denny and Gaines 1990). For example, the acceleration reaction for Collisella pelta represented

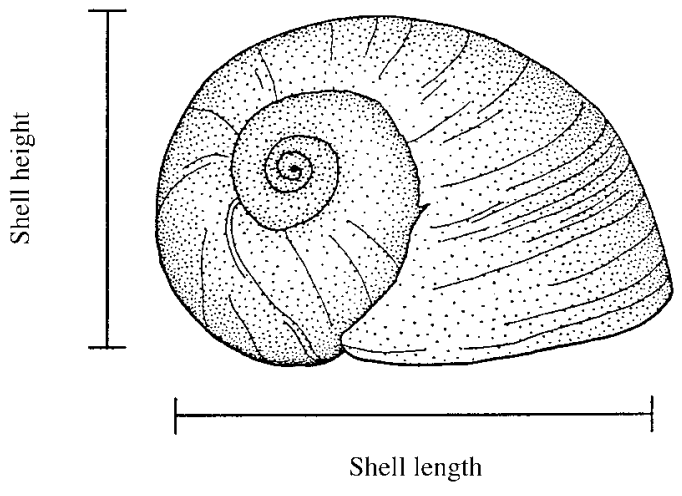

FIG. 1. Measurements of shell height and shell length on Littorina obtusata.

only $10-15 \%$ of the shear force imparted on this limpet (Denny 1985).

Lift acts normal to the direction of flow and is described by (Denny 1988),

$$
\text { Lift }=0.5 C_{1} \rho S_{\mathrm{pl}} U^{2}
$$

where $C_{1}=$ the coefficient of lift and $S_{\mathrm{pl}}=$ the planform area of the snail projected in the direction of lift. For organisms like limpets (Collisella pelta), lift can have a magnitude 1.75 times greater than drag (Denny 1989). Although lift probably exerts an important influence on the risk of dislodgment for Littorina obtusata, its role is unknown. Hence, in this study I focus on drag as the most important hydrodynamic force.

Drag is greater on wave-exposed shores because mean and maximum water velocity is greater than that found on protected shores (Denny 1985, 1988, Denny et al. 1985, Denny and Gaines 1990). In a given flow, snails may reduce drag by (1) reducing the amount of shell area projected normal to flow, (2) behaviorally altering the flow velocity they experience by seeking crevices, and (3) changing shell shape to reduce $C_{\mathrm{d}}$. Here I focus on habitat-specific differences in maximum projected surface area and shell shape.

Shell shape and maximum projected surface area .I characterized differences in shell shape between wave-exposures by measuring the shell height and length of snails (Trussell et al. 1993) from each shore with digital calipers (to $\pm 0.01 \mathrm{~mm}$ [Fig. 1]). Because the direction from which waves strike can vary, I chose the maximum projected surface area of the shell (MPSA) as the orientation exposing the shell to the greatest drag. MPSA was my estimate of shell size and was measured as the side view of the shell (Fig. 1) using image analysis of still video (to $\pm 0.01 \mathrm{~mm}$; NIH Image 1.30).

Adhesive ability: foot size, dislodgment force, and tenacity. - Snails resist dislodgment by adhering to the substratum with the foot. Adhesion is influenced by foot size, and the strength and thickness of the foot mucus (Cotrell 1964). I focused on foot size as the variable most important to a snail's ability to resist 
dislodgment. To determine how adhesive ability varied with wave energy, I made laboratory measurements of foot size and shear dislodgment forces soon after completion of shell measurements. I individually tagged snails and glued (with cyanoacrylate adhesive) a small wire loop to the posterior portion of the shell. Snails were kept in aquaria with running seawater for $24 \mathrm{~h}$. No adverse effects appeared to result from these procedures (Trussell et al. 1993). Individual snails were then placed on a clear Plexiglas platform and lightly tapped to induce maximum adhesion (Branch and Marsh 1978, Etter, 1988a, Trussell et al. 1993). Once the snail was adhering tightly, I inverted the platform and traced the snail's foot onto a sheet of acetate two times before each dislodgment test. The area of these tracings was determined with image analysis of still video (to $\pm 0.01 \mathrm{~mm}$; NIH Image 1.30). The mean of the two foot measurements that corresponded to the maximum dislodgment force obtained during testing was used in statistical analyses.

After tracing the foot, I quickly returned the platform to its original position and connected the wire loop on the snail's shell to a calibrated force transducer (Model FT 03, Grass Instruments) with a monofilament line. I then gradually moved the force transducer $(\approx 20-25$ $\mathrm{g} / \mathrm{s}$ ) in a horizontal direction with a micromanipulator until the snail was dislodged. Dislodgment forces were recorded with a low level DC preamplifier (Model 7P1, Grass Instruments) and a driver amplifier (Model 7DA, Grass Instruments). I performed dislodgment tests four times, on four consecutive days, for all snails from each site with a $24 \mathrm{~h}$ rest period between each trial. The force transducer was calibrated with weights before each testing session. The maximum dislodgment force (in newtons) recorded among the four tests was used in statistical analyses. I calculated snail tenacity (dislodgment force per unit foot area in contact with a surface, in newtons per square meter) by dividing each snail's maximum dislodgment force by the mean of the two estimates of foot size recorded for that force (Trussell et al. 1993).

One potential problem with the dislodgment protocol is that snails with different shell heights may experience different bending moments during testing. I attempted to glue wire loops so that their height above the testing platform was similar for all shells. However, due to the differences in shell height I detected between wave-exposed and protected snails (see Results), the more squat shells of wave-exposed snails may still have experienced a lower bending moment for a given force. Analysis of a restricted data set consisting of waveexposed and protected snails of similar shell height still produced significantly greater dislodgment forces for wave-exposed snails (G. C. Trussell, unpublished data). Hence, habitat-specific differences in dislodgment forces cannot be attributed to differences in bending moments during testing.

\section{Phenotypic plasticity in foot size}

I conducted three experiments to determine whether plasticity contributed to variation in foot size of snails from a wave-exposed and a protected shore.

Reciprocal transplant experiment.-A reciprocal transplant was conducted in the field with snails from Pemaquid Point (E2) and South Harpswell (P2). Snails were collected in early July 1992 as described earlier and returned to the laboratory. Approximately 400 snails from Pemaquid Point and $\approx 700$ from South Harpswell were collected. Snails were tagged with a small dot of colored waterproof marker that was covered with cyanoacrylate glue. Of the snails collected from Pemaquid Point, 183 were returned to Pemaquid Point (EE), and 200 were released at South Harpswell (EP). Of the snails collected from South Harpswell, 505 were released at Pemaquid Point (PE), and 181 were returned to South Harpswell (PP). I released snails (mid-July 1992) by placing individuals on each shore and gently splashing them with water until they attached to the substratum. At Pemaquid Point, snails were placed on Fucoid algae and on bare substratum. At South Harpswell, snails were placed on Ascophyllum nodosum. On each shore, I placed snails at midtidal levels in an area of $\approx 10 \mathrm{~m}^{2}$. Between the last week of September and the first week of October 1992, I recaptured marked snails during three visits to each shore. During each visit, I searched an area that was approximately twice as large as the original transplant zone for 2.5-3 h.

In the laboratory, I measured the foot size of recaptures by placing snails in petri dishes containing sea water and allowing them to attach to the bottom panel (Etter 1988a). I then inverted the petri dish, drained the seawater, and lightly tapped the snail to induce adhesion. I traced the foot size of each snail three times onto sheets of acetate. Shell length was measured (to $\pm 0.01 \mathrm{~mm}$ ) with digital calipers, and foot size tracings were measured with image analysis of still video (to $\pm 0.01 \mathrm{~mm}$; NIH Image 1.30). I used the mean of the three tracings in statistical analyses. For convenience shell length, which is highly correlated (range of $R^{2}=$ 0.91-0.97) with MPSA, was used as my estimate of shell size.

Transplant experiment with protected snails.-This experiment examined the potential influences of both selection and plasticity on the foot size of protected snails transplanted to a wave-exposed and a protected shore. In mid-July 1995 I collected $\approx 325$ snails from South Harpswell (P2). In the laboratory, snails were individually numbered and their foot sizes and shell lengths measured as described above. These measurements allowed me to characterize the phenotypic variation of each transplant group before placing them in the field. Hence, I tested whether differential mortality in each habitat was influenced by the intial foot size of transplants. One hundred twenty-six snails were 


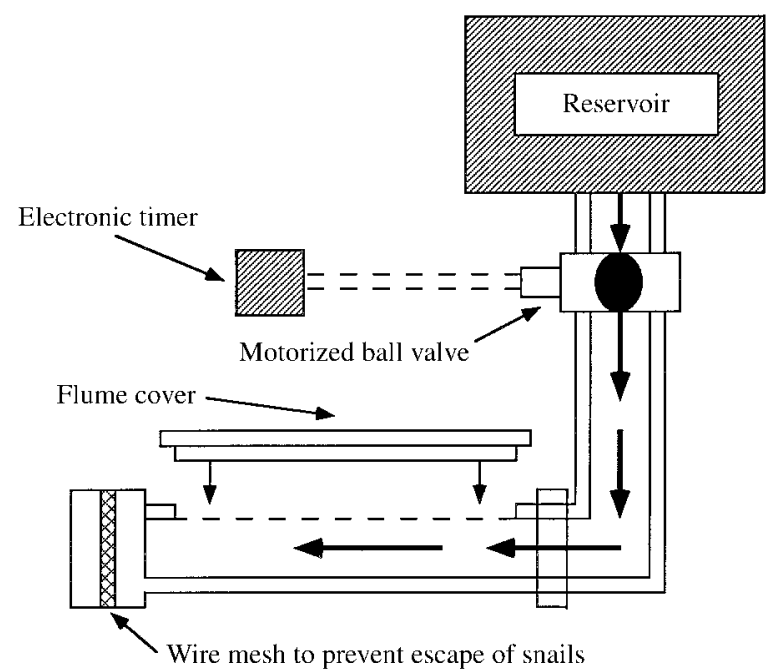

FIG. 2. Diagram of experimental flume system used to raise Littorina obtusata under different flow velocities in the laboratory (not to scale).

transplanted to Pemaquid Point (E2) and 178 were returned to South Harpswell (P2) in mid-July 1995. Between mid-September and mid-October 1995 I recaptured marked snails during two visits at each shore and returned them to the laboratory for measurement of foot size and shell length.

Laboratory flume experiment.-In addition to water velocities associated with breaking waves, other factors in the field may influence foot size. I also tested for phenotypic plasticity in foot size under controlled conditions with a flume experiment manipulating water velocity. Snails from Pemaquid Point (E2) and South Harpswell (P2) were collected and tagged in late May 1992 as described above. Fifty-five snails from each shore were placed in four replicate high-velocity (HF) and four replicate low-velocity (LF) flumes constructed from acrylic tubes that were connected with PVC pipe to a reservoir containing sea water (Fig. 2). Tube length was $0.81 \mathrm{~m}$, with an internal diameter of $58.5 \mathrm{~mm}$. Water flow through tubes was gravity driven, and high and low water velocities were generated by having the height of the reservoirs for each treatment differ. Highvelocity reservoirs were placed $1.45 \mathrm{~m}$ and low-velocity reservoirs were $0.35 \mathrm{~m}$ above the flumes. The frequency of wave events was determined by an electronic timer that opened and closed motorized solenoid ball valves. To avoid overheating the valves, I exposed snails to a wave event every $90 \mathrm{~s}$.

Feeding snails during the course of the experiment required periods of reduced water velocities in the high-velocity flumes. Preliminary attempts at attaching food within the high-velocity flumes proved unsuccessful under conditions of high flow. Consequently, the experiment had feeding periods and wave periods. During feeding periods, $55 \mathrm{~g}$ wet mass of Ulva sp. was placed in each flume by anchoring the algae between the seams of each flume's cover.

The time required for a known volume of water to pass through a flume during a wave event $\left(\mathrm{m}^{3} / \mathrm{s}\right)$ was divided by the cross-sectional area of the pipe $\left(\mathrm{m}^{2}\right)$ to determine water velocities in flumes during wave periods. The mean flow speeds for each treatment were $2.4 \mathrm{~m} / \mathrm{s}$ in high-velocity flumes and $0.5 \mathrm{~m} / \mathrm{s}$ in lowvelocity flumes. These values are in close agreement with those obtained by recording the time required for a parcel of water to travel the length of a flume: 1.7 $\mathrm{m} / \mathrm{s}$ in high-velocity flumes and $0.6 \mathrm{~m} / \mathrm{s}$ in low-velocity flumes. During feeding periods, water velocities in the two treatments were determined by recording the time required for a parcel of water to travel the length of each flume: $0.66 \mathrm{~m} / \mathrm{s}$ in high-velocity flumes and 0.60 $\mathrm{m} / \mathrm{s}$ in low-velocity flumes.

During the course of the experiment, snails in the high-velocity flumes received 25465 high-velocity waves and 24917 low-velocity waves. Snails in lowvelocity flumes received a total of 50382 low-velocity waves. I conducted this experiment from 1 June to 24 August 1992, at which time foot size and shell length was measured as described above. Shell length was used as my estimate of shell size.

\section{Statistical analyses}

Ordinary least squares (OLS) tend to underestimate the slope of allometric relationships with a low $R^{2}$, because of measurement error in the independent variable (LaBarbera 1989). Hence, to determine scaling relationships between shell traits, foot size, and dislodgment force, I conducted reduced-major-axis (RMA) regression on $\log _{(10)}$ transformed data (Ricker 1973, Sokal and Rohlf 1981). To test for departures from isometry between two traits, the $T$ statistic and degrees of freedom were calculated with formulas from McArdle (1988). Because five $t$ tests were involved for each group of comparisons (e.g., shell height vs. length), Bonferroni correction set statistical significance at $\alpha=0.01$. When testing for differences in the slopes and elevations of regression lines with ANCOVA, however, I used OLS regressions because model II ANCOVA techniques are not available (Sokal and Rohlf 1981).

All analyses of covariance (ANCOVA) were conducted with Type III sums of squares on SYSTAT software (Wilkinson 1989). Data were $\log _{(10)}$ transformed to meet the assumptions of ANCOVA (Sokal and Rohlf 1981). A two-factor nested ANCOVA, with sites (random) nested in wave exposure (fixed) was conducted to test for differences in the morphological traits and adhesive ability of field collected snails. For the reciprocal transplant experiment, a one-factor ANCOVA with the experimental treatment as a fixed effect (i.e., site of origin in the field and the shore on which the snails were raised) and shell length as a covariate was conducted to test for differences in the foot sizes of 


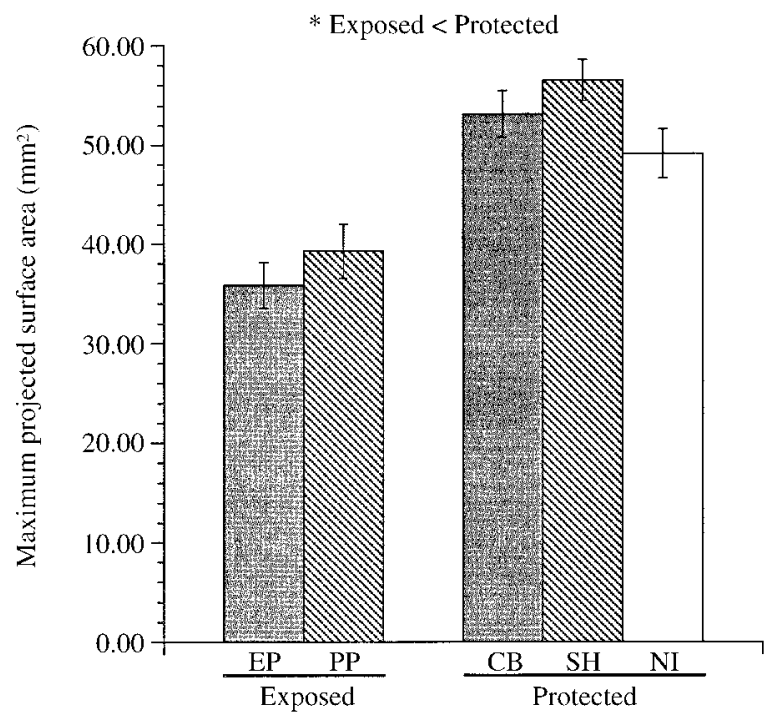

FIG. 3. Mean maximum projected surface area for Littorina obtusata from two wave-exposed and three protected shores. EP = East Point, Nahant, Massachusetts; PP $=$ Pemaquid Point, Maine; $\mathrm{CB}=$ Canoe Beach Cove, Nahant, Massachusetts; $\mathrm{SH}=$ South Harpswell, Maine; NI = Newcastle Island, New Hampshire. $* P<0.05$.

experimental field populations. I conducted a threefactor ANCOVA with replicate flumes (random) nested in flow treatment (high or low) and the wave-exposure of the collection site (wave-exposed or protected) which were fixed effects. Shell length was used as the covariate. Because I wanted to determine whether variation due to treatment and the wave exposure of collection sites was significant relative to variation among replicate flumes, the mean squares of these effects were tested over the mean square for replicate flumes. The interaction term (i.e., flow $\times$ site) was tested over the error mean square. The second transplant experiment with just protected snails was analyzed with a onefactor ANCOVA using shell length as the covariate.

\section{RESUlts}

Morphological variation: wave-exposed vs. protected

Shell size (MPSA) and shape.-The shells of waveexposed snails were smaller (MPSA) than protected snails (nested ANOVA: $F_{(1,3)}=22.91, P=0.017$; Fig. $3)$. Shell height scaled isometrically with both shell length and MPSA (Table 1). However, ANCOVA revealed that for a given MPSA and shell length, the shells of protected snails were taller than wave-exposed snails (Table 2; Fig. 4a, b). Hence, despite isometric scaling between these traits, the shells of wave-exposed snails were more squat than protected snails.

Foot size, dislodgment force and tenacity.-Scaling between foot size and MPSA was isometric for all populations (Table 1), but wave-exposed snails had larger foot sizes than protected snails of similar MPSA (Table 2; Fig. 5). Wave-exposed snails also resisted greater dislodgment forces than protected snails of similar MPSA (Table 2; Fig. 6). For all populations, dislodgment force scaled isometrically with MPSA (Table 1).

Despite the large variation in dislodgment force, ANCOVA revealed that it increased with foot size at the same rate for all populations (Table 2; Fig. 7). Since scaling between dislodgment force and foot size was isometric for all populations, tenacity was similar for all foot sizes (Table 1). ANCOVA on tenacity detected no difference between wave exposures or among sites within each exposure (Table 2; Fig. 7). These results were supported by a nested ANOVA comparing mean tenacities among wave exposures (nested ANOVA: $\left.F_{(1,3)}=0.38, P=0.58\right)$ and sites within exposures (nested ANOVA: $\left.F_{(3,163)}=2.24, P=0.09\right)$. Mean $( \pm 1$ SE) tenacity was similar for all sites: East Point $=8.91$ $\times 10^{3} \mathrm{~N} / \mathrm{m}^{2}( \pm 0.0004)$, Pemaquid Point $=9.92 \times 10^{3}$ $\mathrm{N} / \mathrm{m}^{2}( \pm 0.0005)$, Canoe Beach Cove $=9.15 \times 10^{3} \mathrm{~N} /$ $\mathrm{m}^{2}( \pm 0.0004)$, South Harpswell $=9.84 \times 10^{3} \mathrm{~N} / \mathrm{m}^{2}$ $( \pm 0.0004)$, Newcastle $=1.03 \times 10^{4} \mathrm{~N} / \mathrm{m}^{2}( \pm 0.0004)$. Hence, the greater dislodgment forces of wave-exposed snails were due to their larger foot sizes.

\section{Phenotypic plasticity in foot size}

Foot size of protected snails was plastic. After $\approx 3$ mo in the field, protected snails raised on the waveexposed shore produced a larger foot than conspecifics raised on their native shore (Table 3a; Fig. 8). Bonferroni-adjusted multiple comparisons found that all three experimental groups differed in foot size: EE $>$ PE $>$ PP (all $P<0.0001$ ) (Table 3a; Fig. 8).

Recovery rates of snails were different among experimental groups. For wave-exposed snails, 14 of 183 $(7.6 \%)$ were recovered from the wave-exposed shore (EE) and none were recovered $(0 \%)$ from the protected shore (EP). For protected snails, 105 of 505 (20.7\%) were recovered from the wave-exposed shore (PE) and 15 of $181(8.3 \%)$ were recovered from the protected shore (PP).

The results of the second transplant experiment again revealed that protected snails raised on the wave-exposed shore produce a larger foot than those raised on the protected shore (Table 3b; Fig. 9). This experiment also revealed that little selection on foot size for both transplant groups had occurred. Comparison of the initial measurements of snails recaptured on each shore to the initial measurements of all snails in each transplant group revealed no differences in foot size on both shores (Table 4; Figs. 10a, b).

Like the first transplant experiment, recovery rates were low and the pattern of recapture success the same. Approximately 16\% (20 of 126) of the transplants were recovered on the wave-exposed shore (PE) and $4 \%(7$ of 178) were recovered from the protected shore (PP).

The flume experiment also detected plasticity in foot size, but revealed an asymmetry. Snails from the protected shore raised in high-velocity flow developed a larger foot (28.4\% increase) than conspecifics raised in 
TABLE 1. Reduced-major-axis regression and scaling analyses between morphological attributes and adhesive ability for Littorina obtusata from two wave-exposed (E) and three protected $(\mathrm{P})$ shores. See Results for further explanation. EP = East Point, Massachusetts; $\mathrm{PP}=$ Pemaquid Point, Maine; $\mathrm{CB}=$ Canoe Beach Cove, Massachusetts; $\mathrm{SH}=$ South Harpswell, Maine; NI = Newcastle Island, New Hampshire; MPSA = maximum projected surface area. The $T$ statistics, which test for departures from isometry, and degrees of freedom were calculated following McArdle (1988). For all comparisons, actual slopes were tested against an isometric slope of $b=1$ with the exception of shell height vs. shell length, where $b=$ 0.5 .

\begin{tabular}{|c|c|c|c|c|c|}
\hline Shore & $N$ & Regression & $R^{2}$ & $\mathrm{df}$ & $T$ \\
\hline \multicolumn{6}{|c|}{ Comparison: log shell height $(Y)$ vs. log shell MPSA $(X)$ (Fig. 4a) } \\
\hline $\mathrm{EP}(\mathrm{E} 1)$ & 35 & $\log Y=0.45 \log X+0.01$ & $0.87 * * *$ & 25 & $0.80^{\mathrm{NS}}$ \\
\hline PP (E2) & 25 & $\log Y=0.49 \log X-0.04$ & $0.90 * * *$ & 18 & $0.15^{\mathrm{NS}}$ \\
\hline CB (P1) & 34 & $\log Y=0.57 \log X-0.15$ & $0.93 * * *$ & 24 & $1.28^{\mathrm{NS}}$ \\
\hline SH (P2) & 45 & $\log Y=0.52 \log X-0.07$ & $0.98 * * *$ & 31 & $0.93^{\mathrm{NS}}$ \\
\hline NI (P3) & 29 & $\log Y=0.50 \log X-0.02$ & $0.96 * * *$ & 21 & $0.00^{\mathrm{NS}}$ \\
\hline \multicolumn{6}{|c|}{ Comparison: log shell height $(Y)$ vs. log shell length $(X)$ (Fig. 4b) } \\
\hline EP (E1) & 35 & $\log Y=0.75 \log X-0.02$ & $0.82 * * *$ & 25 & $1.69^{\mathrm{NS}}$ \\
\hline PP (E2) & 25 & $\log Y=0.87 \log X-0.11$ & $0.96 * * *$ & 18 & $1.44^{\mathrm{NS}}$ \\
\hline $\mathrm{CB}(\mathrm{P} 1)$ & 34 & $\log Y=0.83 \log X-0.03$ & $0.95 * * *$ & 24 & $2.02^{\mathrm{NS}}$ \\
\hline SH (P2) & 45 & $\log Y=0.86 \log X-0.04$ & $0.97 * * *$ & 31 & $2.46^{\mathrm{NS}}$ \\
\hline NI (P3) & 30 & $\log Y=0.84 \log X-0.02$ & $0.98 * * *$ & 21 & $2.80^{\mathrm{NS}}$ \\
\hline \multicolumn{6}{|c|}{ Comparison: $\log$ foot size $(Y)$ vs. $\log$ shell MPSA $(X)$ (Fig. 5) } \\
\hline EP (E1) & 35 & $\log Y=1.02 \log X-0.12$ & $0.68 * * *$ & 27 & $0.09^{\mathrm{NS}}$ \\
\hline PP (E2) & 25 & $\log Y=0.98 \log X-0.14$ & $0.75 * * *$ & 19 & $0.08^{\mathrm{NS}}$ \\
\hline $\mathrm{CB}(\mathrm{P} 1)$ & 34 & $\log Y=1.15 \log X-0.51$ & $0.67 * * *$ & 26 & $0.59^{\mathrm{NS}}$ \\
\hline SH (P2) & 45 & $\log Y=1.13 \log X-0.59$ & $0.89 * * *$ & 32 & $1.05^{\mathrm{NS}}$ \\
\hline NI (P3) & 29 & $\log Y=1.05 \log X-0.43$ & $0.90 * * *$ & 21 & $0.35^{\mathrm{NS}}$ \\
\hline \multicolumn{6}{|c|}{ Comparison: $\log$ force $(Y)$ vs. log shell MPSA $(X)$ (Fig. 6) } \\
\hline EP (E1) & 35 & $\log Y=1.46 \log X-2.84$ & $0.43 * * *$ & 29 & $1.25^{\mathrm{NS}}$ \\
\hline PP (E2) & 25 & $\log Y=1.36 \log X-2.74$ & $0.42 * * *$ & 21 & $0.84^{\mathrm{NS}}$ \\
\hline $\mathrm{CB}(\mathrm{P} 1)$ & 34 & $\log Y=1.83 \log X-3.73$ & $0.55 * * *$ & 27 & $2.21^{\mathrm{NS}}$ \\
\hline SH (P2) & 45 & $\log Y=1.55 \log X-3.34$ & $0.62 * * *$ & 35 & $2.02^{\mathrm{NS}}$ \\
\hline NI (P3) & 29 & $\log Y=1.44 \log X-3.08$ & $0.79 * * *$ & 21 & $1.80^{\mathrm{NS}}$ \\
\hline \multicolumn{6}{|c|}{ Comparison: $\log$ force $(Y)$ vs. $\log$ foot size $(X)$ (Fig. 7) } \\
\hline EP (E1) & 35 & $\log Y=1.42 \log X-2.67$ & $0.69 * * *$ & 27 & $1.57^{\mathrm{NS}}$ \\
\hline $\mathrm{PP}(\mathrm{E} 2)$ & 25 & $\log Y=1.38 \log X-2.55$ & $0.77 * * *$ & 19 & $1.40^{\mathrm{NS}}$ \\
\hline $\mathrm{CB}(\mathrm{P} 1)$ & 34 & $\log Y=1.59 \log X-2.91$ & $0.58 * * *$ & 27 & $1.76^{\mathrm{NS}}$ \\
\hline SH (P2) & 45 & $\log Y=1.37 \log X-2.53$ & $0.67 * * *$ & 34 & $1.56^{\mathrm{NS}}$ \\
\hline NI (P3) & 29 & $\log Y=1.36 \log X-2.49$ & $0.82 * * *$ & 21 & $1.64^{\mathrm{NS}}$ \\
\hline
\end{tabular}

low-velocity flow (Table 5; Fig. 11a), but wave-exposed snails showed little change (only a 5.2\% increase) between the two flow regimes (Table 5; Fig. 11b).

While the foot sizes of wave-exposed snails raised in the field and laboratory were similar (ANCOVA, $\left.F_{(2,225)}=1.25, P=0.29\right)$, there were differences between the foot sizes of protected snails raised in the field and lab (ANCOVA, $F_{(3,302)}=157.41, P<$ 0.00001; Fig. 12). Bonferonni-adjusted multiple comparisons found that the response in foot size generally paralleled the risk of dislodgment in each treatment. Protected snails raised on the wave-exposed shore (PE) produced the largest foot sizes, while snails reared in low velocity flumes (PLF) produced the smallest foot sizes $(\mathrm{PE}>\mathrm{PP}=\mathrm{PHF}>\mathrm{PLF}$; all $P<0.00001)$.

\section{DISCUSSION}

Differences in the magnitude of physical constraints set by flow exert a strong influence on snail life history traits (Janson 1982, Brown and Quinn 1988, Etter 1989). For example, wave-exposed Nucella lapillus mature at a smaller size, and offset high mortality rates with increased reproductive effort relative to protected conspecifics (Etter 1989). The influence of flow on these life history traits is probably mediated by the relative risk of dislodgment. Hence, understanding how snails reduce this risk may explain how organisms are able to persist in such a physically harsh environment. For Littorina obtusata, traits such as reduced shell size, increased foot size, and adhesive ability are correlated with increased wave energies, and most likely reflect adaptations to increased hydrodynamic stress.

\section{Shell size and shape}

Drag forces should be greater (assuming constant shape) for larger snails (MPSA) and for snails on waveexposed shores, because water velocities and accelerations are greater (Denny 1985, Denny et al. 1985, Denny and Gaines 1990). Assuming similar shape, the 
TABLE 2. Nested ANCOVA testing the effects of wave exposure (fixed) and site (random; nested in wave exposure) on morphology and adhesive ability for five Littorina obtusato populations. Slopes in all cases were homogeneous; sample sizes are as in Table 1. Protected sites $=\mathrm{P}$; wave-exposed sites $=\mathrm{E}$. NS $=$ not significant.

\begin{tabular}{|c|c|c|c|c|c|}
\hline \multirow[b]{2}{*}{ Source } & \multirow[b]{2}{*}{ df } & \multirow[b]{2}{*}{$\operatorname{MS}\left(\times 10^{-3}\right)$} & \multicolumn{3}{|c|}{ Nested ANCOVA } \\
\hline & & & $F$ & $P$ & E vs. P \\
\hline \multicolumn{6}{|c|}{$\log$ shell height $(Y)$ vs. log shell MPSA $(X)$ (Fig. 4a) } \\
\hline Slope: & 3,160 & 21.00 & 0.92 & NS & \multirow{3}{*}{$\mathrm{P}>\mathrm{E}$} \\
\hline Exposure: & 1,3 & 40.04 & 148.30 & 0.00119 & \\
\hline Site(exposure): & 3,160 & 0.27 & 1.18 & NS & \\
\hline \multicolumn{6}{|c|}{ log shell height $(Y)$ vs. log shell length $(X)$ (Fig. 4b) } \\
\hline Slope: & 3,160 & 0.54 & 2.65 & NS & \multirow{3}{*}{$\mathrm{P}>\mathrm{E}$} \\
\hline Exposure: & 1,3 & 109.30 & 280.26 & 0.00047 & \\
\hline Site(exposure): & 3,160 & 0.39 & 1.93 & NS & \\
\hline \multicolumn{6}{|c|}{$\log$ foot size $(Y)$ vs. log shell MPSA $(X)$ (Fig. 5) } \\
\hline Slope: & 3,159 & 2.30 & 0.75 & NS & \multirow{3}{*}{$\mathrm{E}>\mathrm{P}$} \\
\hline Exposure: & 1,3 & 1001.72 & 248.57 & 0.00055 & \\
\hline Site(exposure): & 3,159 & 4.03 & 1.32 & NS & \\
\hline \multicolumn{6}{|c|}{ log dislodgment force $(Y)$ vs. log shell MPSA $(X)$ (Fig. 6) } \\
\hline Slope: & 3,159 & 0.64 & 0.047 & NS & \multirow{3}{*}{$\mathrm{E}>\mathrm{P}$} \\
\hline Exposure: & 1,3 & 1279.03 & 5329.29 & 0.00001 & \\
\hline Site(exposure): & 3,159 & 0.24 & 0.017 & NS & \\
\hline \multicolumn{6}{|c|}{$\log$ dislodgment force $(Y)$ vs. log foot size $(X)$ (Fig. 7) } \\
\hline Slope: & 3,159 & 1.77 & 0.17 & NS & \multirow{3}{*}{$\mathrm{E}=\mathrm{P}$} \\
\hline Exposure: & 1,3 & 9.97 & 7.50 & NS & \\
\hline Site(exposure): & 3,159 & 1.33 & 0.13 & NS & \\
\hline
\end{tabular}

drag equation indicates that the smaller size (MPSA; [Fig. 3]) of wave-exposed snails will reduce drag under a given set of flow conditions. Wave-exposed snails also had squatter shells (Figs. 4a, b), and this trait, coupled with reduced size, may also increase the availability of sheltered crevices and allow snails to avoid free-stream flows (Denny et al. 1985). Crevice use is common in intertidal snails (Denny et al. 1985, Etter $1988 a$ ) and the size structure of snail populations can be coupled to the size of available crevices. For example, Emson and Faller-Fritsch (1976) increased the size structure of Littorina rudis populations by increasing local crevice size, and Raffaelli and Hughes (1978) found a strong relationship between the size of $L$. rudis and $L$. neritoides and the size of available crevices. Wave-exposed L. obtusata are typically found in or near crevices, while protected snails are found on Ascophyllum nodosum (G. C. Trussell, personal observation). This behavioral difference may reflect differences in the relative risk of dislodgment. The smaller sized, squatter shells of wave-exposed L. obtusata should increase the amount of crevices available for shelter.

The squatter shells of wave-exposed snails may also reduce the shell's coefficients of drag and/or lift; a reduction in either could theoretically reduce the magnitude of these forces. This possibility, though intriguing, is unlikely because the conditions favoring streamlining (such as a predictable direction of flow and the absence of upstream objects [Vogel 1981, Denny 1989]), are unlikely to occur on rocky intertidal shores.
On protected shores, larger sized (MPSA) shells can reduce the risk of crab (Carcinus maenas) predation. Reimchen (1982) found that large-shelled Littorina obtusata were more resistant to C. maenas predation than smaller morphs, and Kaiser et al. (1993) found that $C$. maenas handling time increased with gains in the crosssectional area of artificial Mytilus edulis models. Hence, for L. obtusata both increased size and shell thickness (Palmer 1985, Seeley 1986) can reduce the risk of crab predation.

\section{Foot size, dislodgment force, and tenacity}

Wave-exposed snails required greater forces to dislodge (Fig. 6) than protected snails because of their larger size-specific (MPSA) foot sizes (Fig. 5). Waveexposed Nucella lapillus exhibit similar results (Kitching et al. 1966, Etter 1988a), suggesting that a larger foot is a common adaptation to increased hydrodynamic stress.

Trussell et al. (1993) reported a difference in tenacity between a protected and wave-exposed population of Littorina obtusata. These populations were also studied here, but I found no differences in tenacity (Fig. 7). For all five populations neither wave exposure nor collection site influenced tenacity. Seasonal influences on tenacity (Price 1980) may explain the inconsistency between the two studies. Snails used in Trussell et al. (1993) were collected after the stormier winter season, while those used here were collected in SeptemberOctober. Protected snails exhibited greater tenacity in our earlier study, and seasonal effects may be related 

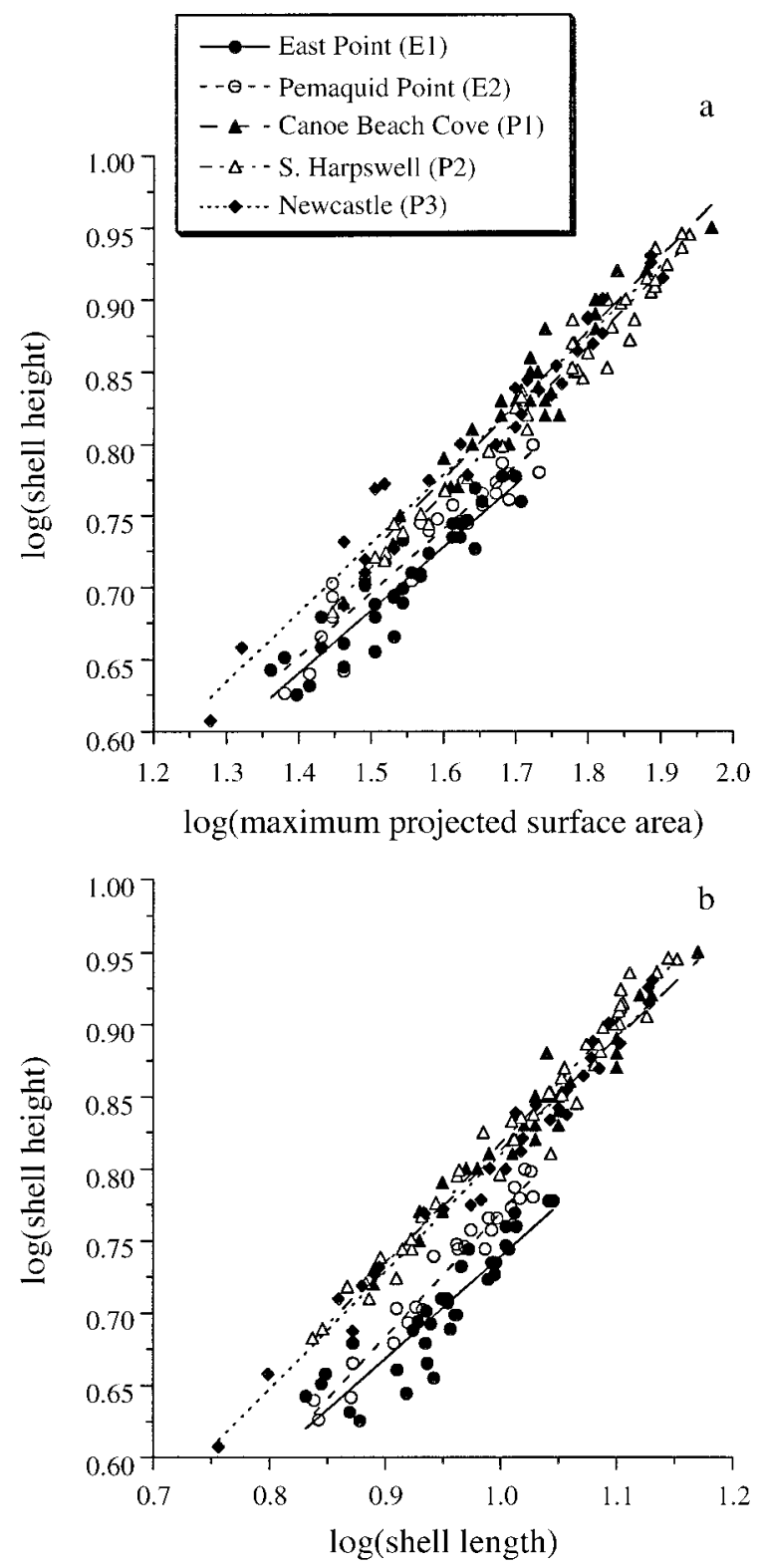

FIG. 4. Log-log plots of (a) shell height ( $\mathrm{mm}$ ) as a function of maximum projected surface area $\left(\mathrm{mm}^{2}\right)$; and (b) shell height $(\mathrm{mm})$ as a function of shell length $(\mathrm{mm})$ for two waveexposed (E) and three protected (P) Littorina obtusata populations. See Table 1 for RMA regressions and scaling analysis, and Table 2 for results of ANCOVA.

to a change in the difficulty of adhering to their preferred substratum Ascophyllum nodosum. Although seasonal influences may be operating, the conclusions of our earlier study were based on only two populations. The consistent pattern for five populations is strong evidence that tenacity does not differ among shores differentially exposed to wave energy. Similar results have been reported for Nucella lapillus (Etter 1998a).

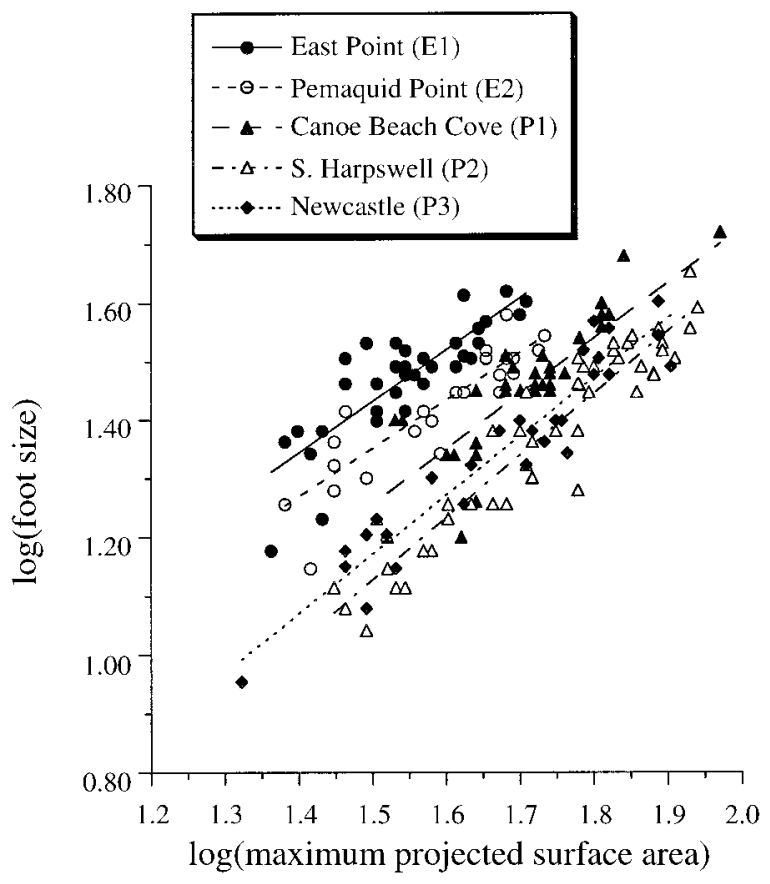

FIG. 5. Log-log plot of foot size $\left(\mathrm{mm}^{2}\right)$ as a function of maximum projected surface area $\left(\mathrm{mm}^{2}\right)$ for two wave-exposed (E) and three protected (P) Littorina obtusata populations. See Table 1 for RMA regressions and scaling analysis, and Table 2 for results of ANCOVA.

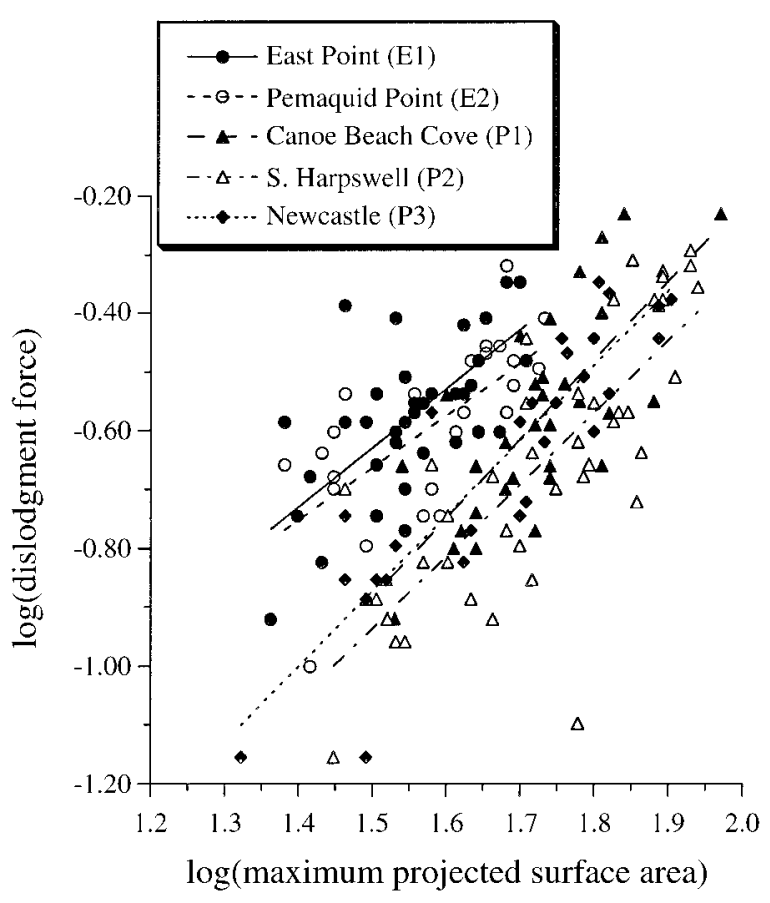

FIG. 6. Log-log plot of dislodgment force (N) as a function of maximum projected surface area $\left(\mathrm{mm}^{2}\right)$ for two waveexposed (E) and three protected (P) Littorina obtusata populations. See Table 1 for RMA regressions and scaling analysis, and Table 2 for results of ANCOVA. 


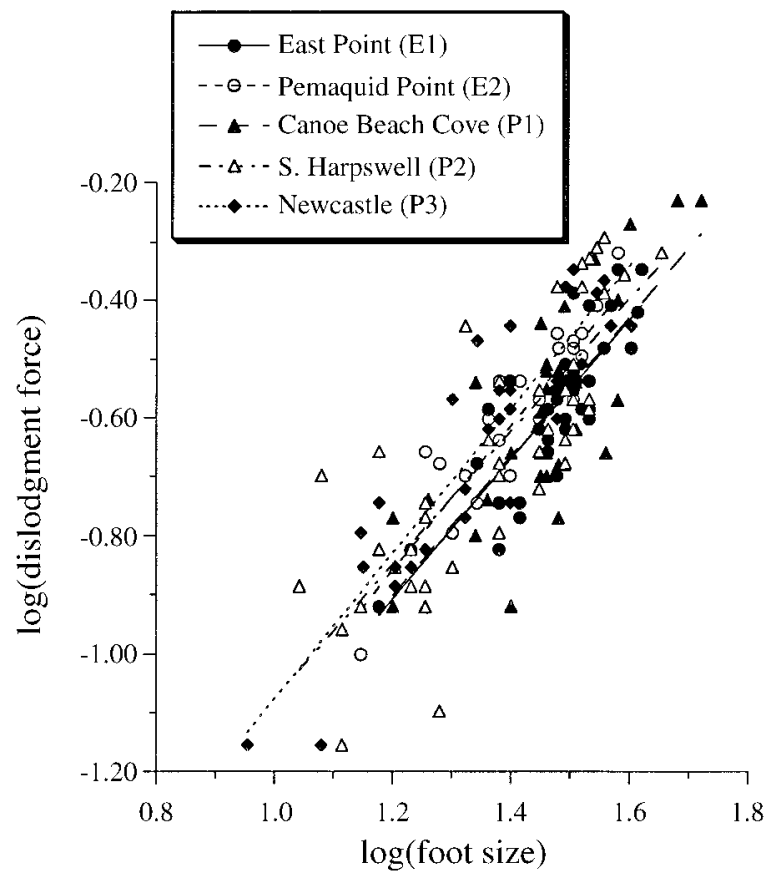

FIG. 7. Log-log plot of dislodgment force (N) as a function of foot size $\left(\mathrm{mm}^{2}\right)$ for two wave-exposed (E) and three protected (P) Littorina obtusata populations. See Table 1 for RMA regressions and scaling analysis, and Table 2 for results of ANCOVA.

\section{Scaling among MPSA, foot size, and dislodgment force}

In this study I used reduced major axis (RMA) regression to examine scaling relationships between various traits. RMA regression is statistically robust and, unlike ordinary least squares (OLS), accounts for measurement error in both the independent and dependent variable (Ricker 1973). In an earlier study (Trussell et al. 1993), we examined scaling relationships for OLS regressions but did so after making estimates of measurement error in the independent variables. Hence, regressions were corrected when measurement error in the independent variable was deemed large.

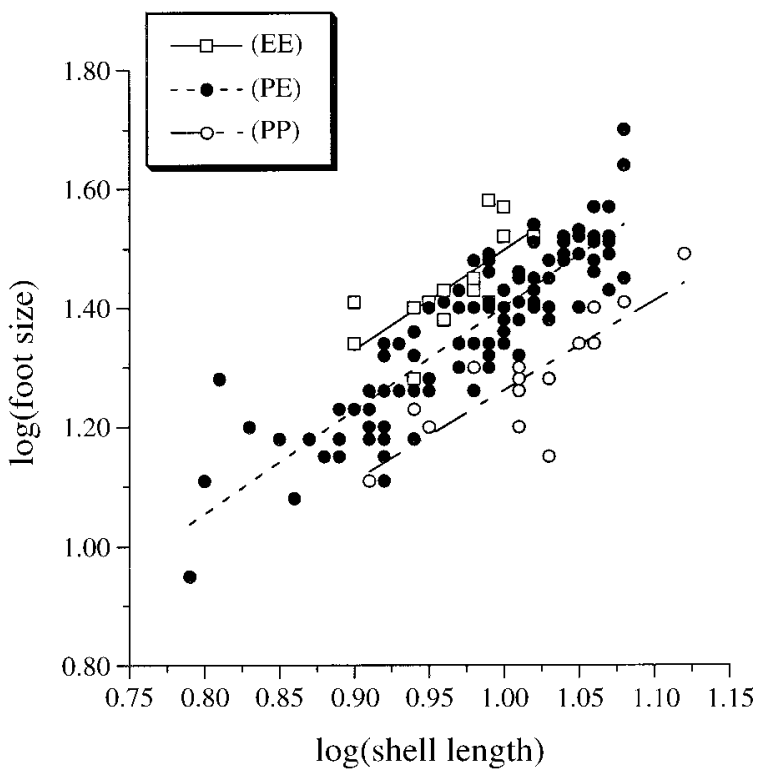

FIG. 8. Log-log plot of foot size $\left(\mathrm{mm}^{2}\right)$ as a function of shell length $(\mathrm{mm})$ for Littorina obtusata reciprocally transplanted between a wave-exposed and protected shore in 1993. $\mathrm{EE}=$ Wave-exposed snails/wave exposed shore; PE = Protected snails/wave-exposed shore; $\mathrm{PP}=$ Protected snails/protected shore. See Table 3a for OLS regressions and results of ANCOVA.

The use of RMA produced some results that contrasted with our earlier study. However, when I performed RMA regressions on the Trussell et al. (1993) data set, the results between the two studies were completely consistent (G. C. Trussell, unpublished data). For this reason, and the statistical robustness of RMA, I view this method as more appropriate for examining the scaling relationships described below.

Both foot size and dislodgment force scaled isometrically with shell size (MPSA), and dislodgment force scaled isometrically with foot size. Assuming that MPSA is proportional to speed-specific drag, these scaling relationships imply that the risk of dislodgment does not increase for snails as they grow, and that dis-

TABLE 3. (a) Results of ordinary least squares (OLS) regression analyses and ANCOVA for wave-exposed snails transplanted to a wave-exposed shore (EE; $N=14$ ) and protected snails reciprocally transplanted between a protected $(\mathrm{PP} ; N=15)$ and wave-exposed (PE; $N=105$ ) shore in 1993. (b) Results of OLS regression analyses and ANCOVA for protected snails transplanted to a wave-exposed (PE; $N=20)$ and protected shore (PP; $N=7)$ in 1995.

\begin{tabular}{|c|c|c|c|c|c|c|c|}
\hline \multicolumn{3}{|c|}{ Regression } & \multicolumn{5}{|c|}{ ANCOVA } \\
\hline Group & Equation & $R^{2}$ & Source & df & MS $\left(\times 10^{-3}\right)$ & $F$ & Comparison \\
\hline \multicolumn{8}{|c|}{ a) $\log$ foot size $(Y)$ vs. log shell length $(X)$} \\
\hline $\begin{array}{l}\text { EE } \\
\text { PE } \\
\text { PP }\end{array}$ & $\begin{array}{l}\log Y=1.72 \log X-0.22 \\
\log Y=1.73 \log X-0.33 \\
\log Y=1.54 \log X-0.28\end{array}$ & $\begin{array}{l}0.51 * * * \\
0.77 * * * \\
0.66 * * *\end{array}$ & $\begin{array}{l}\text { Slope } \\
\text { Elev. }\end{array}$ & $\begin{array}{l}2,128 \\
2,130\end{array}$ & $\begin{array}{r}0.65 \\
206.38\end{array}$ & $\begin{array}{l}0.16^{\mathrm{NS}} \\
52.94^{* * * *}\end{array}$ & $\mathrm{EE}>\mathrm{PE}>\mathrm{PP}$ \\
\hline \multicolumn{8}{|c|}{ b) log foot size $(Y)$ vs. log shell length $(X)$} \\
\hline $\begin{array}{l}\mathrm{PE} \\
\mathrm{PP}\end{array}$ & $\begin{array}{l}\log Y=2.27 \log X-0.93 \\
\log Y=1.83 \log X-0.57\end{array}$ & $\begin{array}{l}0.89 * * * \\
0.85 * * *\end{array}$ & $\begin{array}{l}\text { Slope } \\
\text { Elev. }\end{array}$ & $\begin{array}{l}1,23 \\
1,24\end{array}$ & $\begin{array}{r}1.18 \\
30.32\end{array}$ & $\begin{array}{c}0.70^{\mathrm{NS}} \\
18.17^{* * *}\end{array}$ & $\mathrm{PE}>\mathrm{PP}$ \\
\hline
\end{tabular}

*** $P<0.001$, **** $P<0.0001$. 
TABLE 4. Results of ordinary least squares regression analyses and ANCOVA on protected snails transplanted to a protected and wave-exposed shore in 1995. This analysis compares initial measurements of foot size for all transplants on each shore ("Initial transplant") to initial measurements of snails that I was able to recapture ("Initial/recapture"). Phenotypic clouds are presented in Fig. 10.

\begin{tabular}{|c|c|c|c|c|c|c|}
\hline \multirow{2}{*}{\multicolumn{3}{|c|}{ Regression: $\log$ foot size $(Y)$ vs. log shell length $(X)$}} & \multicolumn{4}{|c|}{ ANCOVA } \\
\hline & & & \multirow[b]{2}{*}{ Source } & \multirow[b]{2}{*}{ df } & \multirow{2}{*}{$\left(\times \begin{array}{c}\text { MS } \\
\left(0^{-3}\right)\end{array}\right.$} & \multirow[b]{2}{*}{$F$} \\
\hline Treatment & Equation & $R^{2}$ & & & & \\
\hline \multicolumn{7}{|l|}{ Protected shore } \\
\hline Initial/transplant & $\log Y=1.81 \log X-0.50$ & $0.71 * * *$ & Slope & 1,177 & 3.41 & $0.52^{\mathrm{NS}}$ \\
\hline Initial/recapture & $\log Y=2.19 \log X-0.80$ & $0.98 * * *$ & Elev. & 1,177 & 2.50 & $0.39^{\mathrm{NS}}$ \\
\hline \multicolumn{7}{|c|}{ Wave-exposed shore } \\
\hline Initial/transplant & $\log Y=1.75 \log X-0.42$ & $0.79 * * *$ & Slope & 1,142 & 0.05 & $0.01^{\mathrm{NS}}$ \\
\hline Initial/recapture & $\log Y=1.78 \log X-0.45$ & $0.78 * * *$ & Elev. & 1,142 & 0.07 & $0.02^{\mathrm{NS}}$ \\
\hline
\end{tabular}

lodgment force in shear is proportional to drag. This argument involves two assumptions: (1) the absence of significant velocity gradients (i.e., boundary layers); and (2) a constant $C_{\mathrm{d}}$. Both issues are discussed in detail by Denny et al. (1985).

The boundary layer is the distance, $\delta$, from the substratum that water velocity attains $99 \%$ of its freestream value (Vogel 1981). The turbulent boundary layers typical of wave-swept rocky shores have steep velocity profiles. Thus, the most dramatic velocity changes occur closest to the substratum and become less important farther away from the substratum (Denny et al. 1985). Rough estimates on the thickness of intertidal boundary layers led Denny et al. (1985) to conclude that they are much thinner than the height of the organisms they studied. Hence, it is generally accepted that the water velocities and accelerations experienced by intertidal snails are independent of their height and size.

$C_{\mathrm{d}}$ is influenced by shape and the $\mathrm{Re}$ of the flow

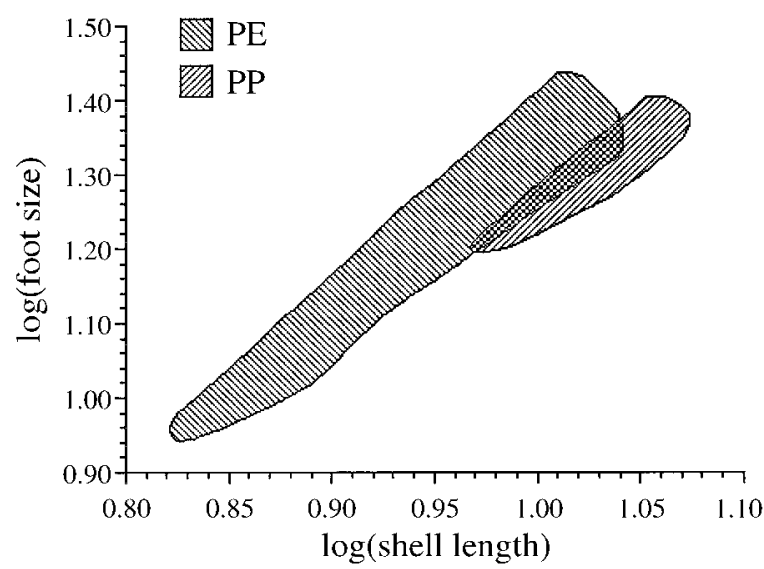

FIG. 9. Log-log plot of foot size $\left(\mathrm{mm}^{2}\right)$ as a function of shell length $(\mathrm{mm})$ for protected Littorina obtusata transplanted to a wave-exposed and protected shore in 1995. PE = Protected snails/wave-exposed shore, $\mathrm{PP}=$ Protected snails/ protected shore. See Table $3 \mathrm{~b}$ for OLS regressions and results of ANCOVA.

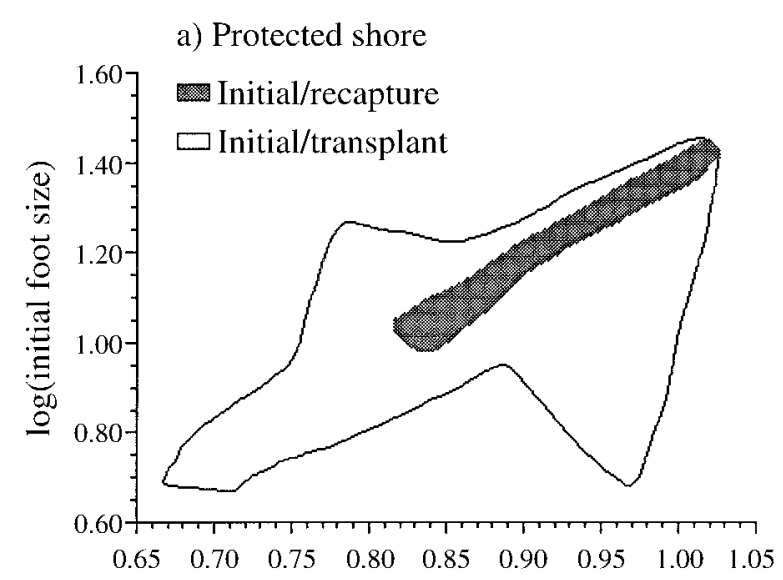

b) Wave-exposed shore

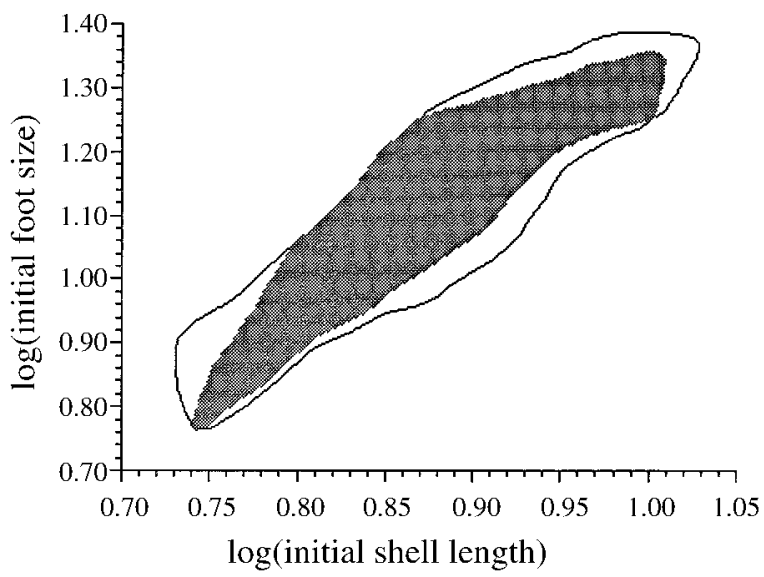

FIG. 10. Phenotypic clouds for log-log plot of foot size $\left(\mathrm{mm}^{2}\right)$ as a function of shell length (mm) for protected Littorina obtusata raised in the field on (a) a protected and (b) a wave-exposed shore in 1995. "Initial/transplant" refers to measurements made on all snails in each transplant group before they were placed at each site. "Initial/recapture" refers to the initial measurements made on snails I was able to recapture. See Table 4 for OLS regressions and results of ANCOVA. 
TABLE 5. Results of OLS regression analyses and ANCOVA for wave-exposed (E) and protected (P) snails raised under conditions of high (HF) and low (LF) velocity flow. Sample sizes: EHF $(N=106)$; ELF $(N=111)$; PHF $(N=95)$; PLF $(N=92)$. The inequality sign between site labels distinguishes groups that differed significantly $($ all $P<0.0001)$ by Bonferroni-adjusted multiple comparisons.

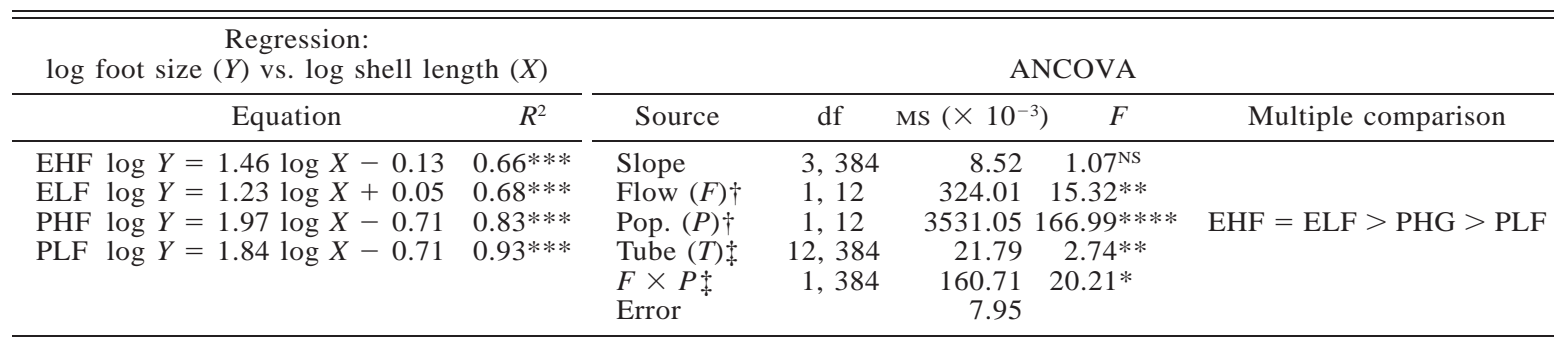

$* P<0.05 ; * * P=0.01$, *** $P<0.001, * * * * P<0.0001$.

$\dagger \mathrm{MS}$ tested over $\mathrm{MS}_{\text {tube }}$; $\ddagger$ MS tested over $\mathrm{MS}_{\text {error }}$.

environment, and can therefore be influenced by size. Hence the assumption of a constant $C_{\mathrm{d}}$ should be viewed with caution (Denny et al. 1985). However, for the limpets studied by Denny et al. (1985) $C_{\mathrm{d}}$ did not change appreciably; $C_{\mathrm{d}}$ changed from 0.7 to 0.5 over an $\mathrm{Re}$ range of $10^{4}$ to $10^{5}$. Although more work is needed to determine variation in $C_{\mathrm{d}}$ with $\mathrm{Re}$ for intertidal organisms, Denny et al. (1985) concluded that this variation is probably very small for blunt objects like snail shells.

\section{Phenotypic plasticity in foot size}

The foot size of protected snails was plastic; protected snails raised on the wave-exposed shore developed a larger foot than those raised on their native shore (Figs. 8, 9). Although increased wave energy probably induced this response, other factors that are influenced by wave energy may also operate on foot size. However, the flume experiment provides the first conclusive data that larger foot sizes are induced by increased hydrodynamic stress associated with increased water velocity. Hence, similar cues were probably operating on field transplants.

The flume experiment also revealed an asymmetry in the plasticity: while protected snails produced a larger foot under high flow (Fig. 11a), wave-exposed snails exhibited no significant differences in foot size between flow treatments (Fig. 11b). Transplant experiments between high and low wave energy environments produced a similar pattern in the plasticity of foot size in Nucella lapillus (Etter 1988a) and of tissue strength in Halichondria panicea (Palumbi 1984). The consistency between these studies supports the hypothesis that natural selection should favor an asymmetry in phenotypic plasticity when there is an asymmetry in the risk of improperly adjusting to an unpredictable cue like wave energy (Etter 1988a). For example, if wave-exposed snails reduced foot size in response to prolonged calm periods on wave-exposed shores, they may experience a greater risk of dislodgment when wave energies return to typical levels.

The change in foot size may represent developmental conversion, but these responses are typically "all-ornothing" responses that produce discrete rather than continuous phenotypic variation. The induced change in foot size of protected snails was continuous with foot size paralleling the relative risk of dislodgment in each treatment (Fig. 12). Hence, the response in foot size is most consistent with phenotypic modulation. Although the inducer and pattern of the plasticity are clear, the precise mechanism underlying this change is not. The plasticity may arise due to differences in growth rates between flow treatments. For shell traits, plasticity in both thickness and shape can be associated with reduced growth rates resulting from differences in food availability (Kemp and Bertness 1984, Boulding and Hay 1993) or reduced feeding activity (Appleton and Palmer 1988, Palmer 1990).

\section{The selection hypothesis}

In the field, different selection pressures operating in each habitat could also account for the change in foot size. Directional selection by increased hydrodynamic stress on wave-exposed shores should favor snails having a larger foot (Kitching et al. 1966). On protected shores, a large foot can (1) increase vulnerability to desiccation stress (Vermeij 1971a, b, 1973, Etter 1988b), and (2) reduce a snail's ability to retract into the shell (Palmer, 1990), thereby increasing vulnerability to apertural probing by crab predators. Hence, directional selection on protected shores would favor a small foot.

Three points argue against the selection hypothesis as an explanation of my results. First, in addition to showing plasticity in foot size (Fig. 9), the second transplant experiment also detected little, if any, selection on foot size in either habitat. On the protected shore, the lower bounds of the initial phenotypic cloud of all transplants should be occupied by recaptures if directional selection favoring smaller foot sizes was operating. If directional selection favored larger foot sizes on the wave-exposed shore, then the initial measurements of recaptures should be in the upper bounds of the phenotypic cloud for all transplants, because 

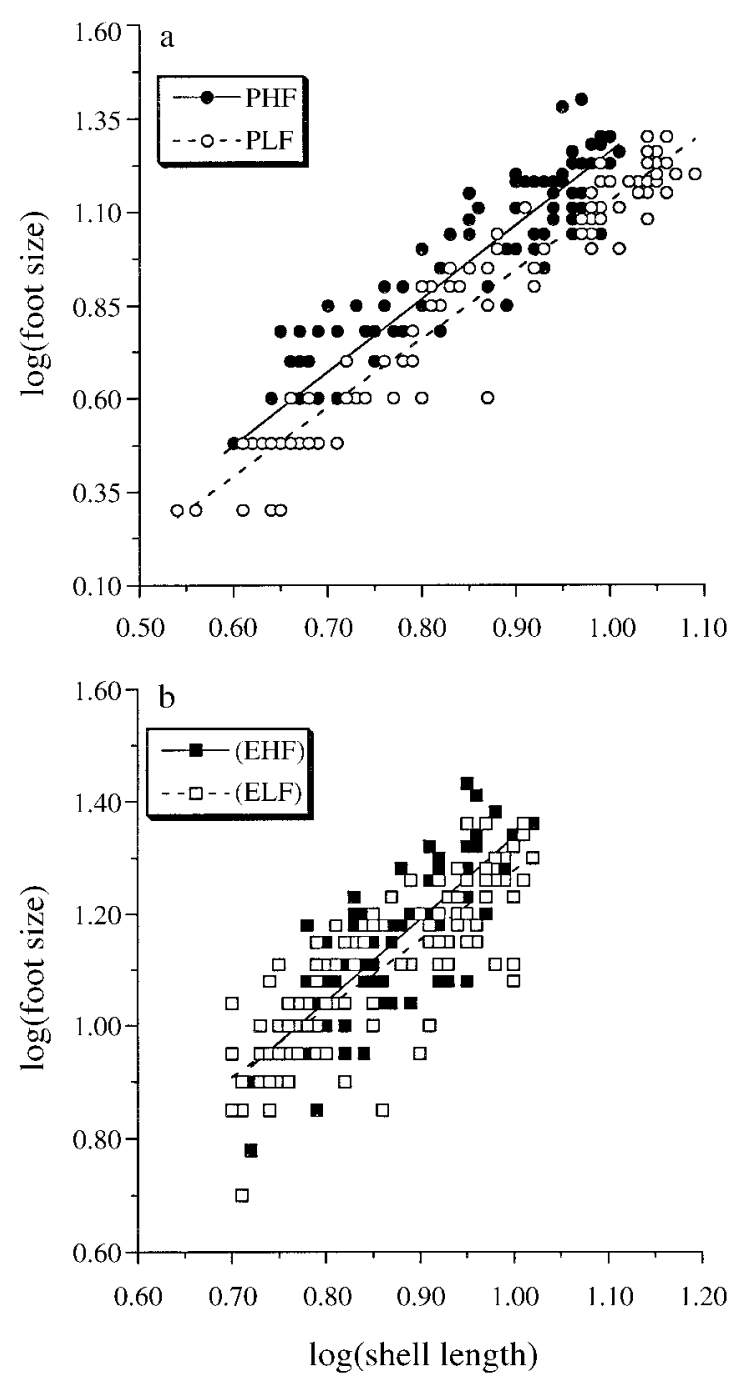

FIG. 11. Log-log plots of foot size $\left(\mathrm{mm}^{2}\right)$ as a function of shell length (mm) for (a) protected and (b) wave-exposed Littorina obtusata raised under high and low velocity flow. $\mathrm{PHF}=$ protected snails/high flow; PLF $=$ protected snails $/$ low flow; EHF = wave-exposed snails/high flow; ELF = wave-exposed snails/low flow. See Table 5 for OLS regressions and results of ANCOVA.

selection can only act on the available phenotypic variation. In both cases, these criteria are not met. Comparison of the initial measurements of control snails recovered on the protected shore to the initial measurements of all snails transplanted there show that recaptures were not particularly small-footed (Fig. 10a). Similarly, protected snails recovered on the waveexposed shore were not particularly large-footed relative to the foot sizes of all snails originally placed there (Fig. 10b). Hence, my results indicate that little selection was operating on foot size in each habitat.

Second, assume that variation in the foot size of snails raised in low velocity flumes (PLF in Fig. 12) was not influenced by directional selection. This as-

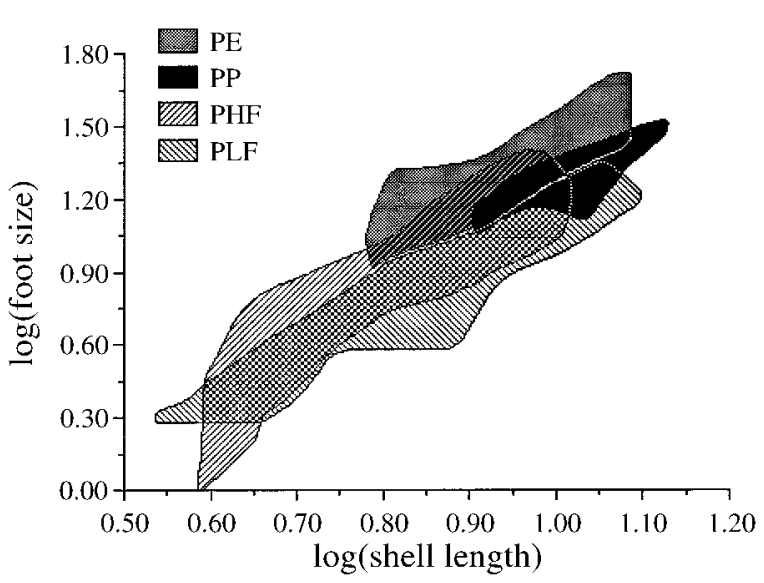

FIG. 12. Phenotypic clouds for $\log -\log$ plot of foot size $\left(\mathrm{mm}^{2}\right)$ as a function of shell length $(\mathrm{mm})$ for protected Littorina obtusata raised in the field on a wave-exposed (PE) and protected shore (PP) in 1993, and under high (PHF) and low (PLF) velocity flow in the laboratory.

sumption is reasonable, because the likely selective agents (crab predation and desiccation stress) were not present. If directional selection favors smaller foot sizes in protected snails raised on the protected shore (PP in Fig. 12), the phenotypic cloud characterizing variation in PP foot size should be below that of snails raised in low velocity flumes (PLF). Fig. 12 shows that this is not the case; foot sizes of PP snails are larger than those of PLF snails.

Third, comparison of protected snails raised in the field and lab also argue against selection (Figs. 8, 9, 12). In each experiment snails were randomly assigned to each treatment, so initial phenotypic variation in foot size was probably similar between treatments. If selection created the differences in foot size between treatments, there should be differences in foot sizes among experimental treatments, and substantial phenotypic overlap between (1) protected snails raised on both shores in the field, and (2) protected snails raised under both laboratory flow treatments, because selection must act on the available phenotypic variation (Etter 1988a). There is clearly little phenotypic overlap for protected snails from all three experiments (Figs. $8,9,12)$, indicating a plastic shift in the phenotypic pool (Etter 1988a).

In summary, phenotypic plasticity represents the best explanation for the differences in foot size found in my experiments. I do not suggest that selection on foot size in both habitats does not occur. Both plasticity and selection surely have important roles in maintaining the morphological differentiation of populations along wave-exposure gradients. However, it may be during unusual events, such as large storms (G. C. Trussell, unpublished manuscript) on wave-exposed shores or high crab densities on protected shores, that selection assumes a more prominent role. 


\section{Is the plasticity in foot size adaptive?}

Phenotypic modulation is not always adaptive, and may simply reflect the nonadaptive impact of the environment on the physicochemical processes of the organism (Smith-Gill 1983, Stearns 1989). To be adaptive, plasticity of a trait must confer some benefit to the organism in the local environment, such as improved survival, growth, or reproduction. For example, predator-induced increases in snail shell thickness are known for three species (Appleton and Palmer 1988, Palmer 1990, Trussell 1996). These induced responses are interpreted as adaptive because (1) variation in shell thickness often parallels the threat of crab predation (i.e., protected snails have thicker shells than waveexposed ones); (2) the response was induced by specific cues (i.e., snails produced thicker shells in the presence of a cue indicating predation risk); and (3) thicker shells are known to deter crab predation (Palmer 1985, Seeley 1986).

Similarly, the plastic increase in foot size may be adaptive in reducing the risk of dislodgment, because a larger foot promotes increased adhesive ability (Kitching et al. 1966, Etter 1988a, Trussell 1993). Hence, a larger foot should improve survivorship in hydrodynamically stressful environments. In my transplant experiments, the recovery rates of snails contradict this point, because one would expect recovery rates to be highest for snails on their native shore. However, the different recovery rates for PE vs. PP snails probably reflect inherent differences in the recapture success of each morph on each shore. The light-colored (e.g., yellow) morphs of PE snails were much easier to find at the wave-exposed site than native snails (EE), which were exclusively black or brown and thus more cryptic. Despite intensive searches, thick blankets of Ascophyllum made it difficult to find both PP and EP snails on the protected shore. I did not recover any EP snails on the protected shore, and I suspect that crab predation was primarily responsible. A pilot experiment at another protected site supports this conclusion. Only two days after releasing tagged wave-exposed snails, I found many shell fragments containing my colored tags.

Finally, since no major storm events occurred during either transplant, wave energies did not reach critical levels. Hence, despite the fact that EE snails had larger foot sizes than PP snails in the first experiment (both at the beginning and the end of the experiment), the change in foot size of PE snails may have been sufficient for the wave energies they experienced during their stay in the field.

In summary, there is a clear association between wave energy and the shell size, foot size, and adhesive ability of Littorina obtusata. Habitat-specific differences in these traits can reduce the risk of dislodgment on wave-exposed shores and of crab predation on protected shores. Although selection is often invoked to explain morphological differentiation across gradients in wave energy, plastic increases in foot size represent an important adaptation to increased hydrodynamic stress. The asymmetry in the plasticity is consistent with the potential risk associated with making adjustment errors in unpredictable environments like those found on wave-swept shores.

\section{ACKNOWLEDGMENTS}

The comments and advice of M. Patterson, R. Olson, P. Sale, W. Sobczak, and J. Taylor aided in all aspects of this study. R. Etter and S. Gaines were especially helpful in improving previous drafts. I also thank H. Howell of the Coastal Marine Laboratory and P. Lavoie for help with flume construction. J. Witman and J. Ayers provided laboratory space and insight during my extended stay at Northeastern University's Marine Science Center at Nahant. S. Orringer was especially helpful in the laboratory, and C. Chester provided the snail drawings. This work was supported by grants from the Hawaiian Malacological Society, the Lerner-Gray Fund of the American Museum of Natural History, a Grant-in-aidof-Research from Sigma Xi, the Scientific Research Society, the Center for Marine Biology (UNH), the Central University Research Fund (UNH), the Agricultural Experiment Station (UNH), a Summer Teaching Assistant Fellowship (UNH), and an NSF Dissertation Improvement Grant (DEB-9412305). This paper is contribution number 2044 from the Virginia Institute of Marine Science.

\section{Literature Cited}

Appleton, R. D., and A. R. Palmer. 1988. Water-borne stimuli released by crabs and damaged prey induce more predatorresistant shells in a marine gastropod. Proceedings of the National Academy of Sciences, USA 85:4387-4391.

Bequaert, J. C. 1943. The genus Littorina in the western Atlantic. Johnsonia 7:1-27.

Boulding, E. G., and T. K. Hay, 1993. Quantitative genetics of shell form of an intertidal snail: constraints on shortterm responses to selection. Evolution 47:576-592.

Bradshaw, A. D. 1965. Evolutionary significance of phenotypic plasticity in plants. Advanced Genetics 13:115155.

Branch, G. M., and A. C. Marsh. 1978. Tenacity and shell shape in six Patella species: adaptive features. Journal of Experimental Marine Biology and Ecology 34:111-130.

Bronmark, C., and J. G. Miner. 1992. Predator-induced phenotypical change in body morphology in Crucian carp. Science 258: $1348-1350$.

Brown, K. M., and J. F. Quinn. 1988. The effect of wave disturbance on growth in three species of intertidal gastropods. Oecologia (Berlin) 75:420-425.

Cottrell, A. H. 1964. The mechanical properties of matter. John Wiley and Sons, New York, New York, USA.

Denny, M. W. 1985. Waves forces on intertidal organisms: a case study. Limnology and Oceanography 30:1171-1187.

. 1987. Life in the maelstrom: the biomechanics of wave-swept rocky shores. Trends in Ecology and Evolution 2:61-66.

. 1988. Biology and the mechanics of the wave-swept environment. Princeton University Press, Princeton, New Jersey, USA.

1989. A limpet shell shape that reduces drag: laboratory demonstration of a hydrodynamic mechanism and an exploration of its effectiveness in nature. Canadian Journal of Zoology 67:2098-2106.

1991. Biology, natural selection and the prediction of maximal wave-induced forces. South African Journal Marine Science 10:353-363. 
Denny, M. W., T. L. Daniel, and M. A. R. Koehl. 1985 Mechanical limits to size in wave-swept organisms. Ecological Monographs 55:69-102.

Denny, M. W., and S. D. Gaines. 1990. On the prediction of maximal intertidal wave forces. Limnology and Oceanography 35:1-15.

Dodson, S. I. 1989. Predator-induced reaction norms BioScience 39:447-452.

Dudgeon, S. R., and A. S. Johnson. 1992. Thick versus thin: thallus morphology and tissue mechanics influence differential drag and dislodgement of two co-dominant seaweeds. Journal of Experimental Marine Biology and Ecology 165: 23-43.

Emson, R. H., and R. J. Faller-Fritsch. 1976. An experimental investigation into the effect of crevice availability on abundance and size structure in a population of Littorina rudis (Maton): Gastropoda: Prosobranchia. Journal of Experimental Marine Biology and Ecology 23:285-297.

Endler, J. A. 1986. Natural selection in the wild. Princeton University Press, Princeton, New Jersey, USA.

Etter, R. J. 1988a. Asymmetrical developmental plasticity in an intertidal snail. Evolution 42:322-334.

. 1988b. Physiological stress and color polymorphism in the intertidal snail Nucella lapillus. Evolution 42:660680 .

. 1989. Life history variation in the intertidal snail Nucella lapillus across a wave-exposure gradient. Ecology 70:1857-1876

Harvell, C. D. 1984. Predator-induced defense in a marine bryozoan. Science 224:1357-1359.

Janson, K. 1982. Genetic and environmental effects on the growth rate of Littorina saxatilis. Marine Biology 69:7378 .

Judge, M. L. 1988. The effects of increased drag on Lottia gigantea (Sowerby 1834) foraging behavior. Functional Ecology 2:363-369.

Kaiser, M. J., R. N. Hughes, and R. B. Gibson. 1993. Factors affecting diet selection in the shore crab, Carcinus maenas (L.). Animal Behavior 45:83-92.

Kemp, P., and M. D. Bertness. 1984. Snail shape and growth rates: evidence for plastic shell allometry in Littorina littorea. Proceedings of the National Academy of Sciences, USA 81:811-813.

Kitching, J. A., and J. Lockwood. 1974. Observations on shell form and its ecological significance in Thaisid gastropods of the genus Lepsiella in New Zealand. Marine Biology 28:131-144.

Kitching, J. A., L. Muntz, and F. J. Ebling. 1966. The ecology of Lough Ine. XV. The ecological significance of shell and body forms in Nucella. Journal of Animal Ecology 35:113126.

LaBarbera, M. 1989. Analyzing body size as a factor in ecology and evolution. Annual Review of Ecology and Systematics 20:97-117.

Levins, R. 1968. Evolution in changing environments Princeton University Press, Princeton, New Jersey, USA.

Lewis, J. R. 1964. The ecology of rocky shores. English University Press, London, UK.

Lively, C. M. 1986a. Canalization vs. developmental conversion in a spatially variable environment. American Naturalist 128:561-572.

- 1986b. Predator-induced shell dimorphism in the acorn barnacle Chthamalus anisopoma. Evolution 40:232242.

Lubchenco, J. L., and B. A. Menge. 1978. Community development and persistence in a low rocky intertidal zone. Ecological Monographs 48:67-94.

McArdle, B. H. 1988. The structural relationship: regression in biology. Canadian Journal of Zoology 66:2329-2339.
Morison, J. R., M. P. O’Brien, J. W. Johnson, and S. A. Schaaf. 1950. The forces exerted by surface waves on piles. Petroleum Transactions AIME 189:149-157.

Newell, R. C. 1979. Biology of intertidal animals. Marine Ecological Surveys, Faversham, UK.

Newman, R. A. 1988a. Genetic variation for larval anuran (Scaphiopus couchii) development time in an uncertain environment. Evolution 42:763-773.

. 1988b. Adaptive plasticity in development of Scaphiopus couchii tadpoles in desert ponds. Evolution 42: 774-783.

Palmer, A. R. 1985. Adaptive value of shell variation in Thais lamellosa: effect of thick shells on vulnerability to and preference by crabs. Veliger 27:349-356.

- 1990. Effect of crab effluent and scent of damaged conspecifics on feeding, growth, and shell morphology of the Atlantic dogwhelk Nucella lapillus (L.). Hydrobiologia 193: $155-182$

Palumbi, S. R. 1984. Tactics of acclimation: morphological changes of sponges in an unpredictable environment. Science 225: $1478-1480$.

Price, H. A. 1980. Seasonal variation in the strength of byssal attachment of the common mussel, Mytilus edulis. Journal of the Marine Biological Association, UK 60:1035-1037.

Raffaelli, D. G., and R. N. Hughes. 1978. The effect of crevice size and availability on populations of Littorina rudis and Littorina neritoides. Journal of Animal Ecology 74:71-83.

Reimchen, T. E. 1982. Shell size divergence in Littorina mariae and L. obtusata and predation by crabs. Canadian Journal of Zoology 60:687-695.

Ricker, W. E. 1973. Linear regressions in fishery research. Journal Fisheries Research Board, Canada 30:409-434.

Sebens, K. P. 1981. Recruitment in a sea anemone population: juvenile substrate becomes adult prey. Science 213: 785-787.

Seeley, R. H. 1986. Intense natural selection caused a rapid morphological transition in a living marine snail. Proceedings of the National Academy of Sciences 83:6897-6901.

Smith-Gill, S. J. 1983. Developmental plasticity: developmental conversion vs. phenotypic modulation. American Zoologist 23:47-55.

Sokal, R. R., and F. J. Rohlf. 1981. Biometry. W. H. Freeman and Company, New York, New York, USA.

Stearns, S. C. 1989. The evolutionary significance of phenotypic plasticity. BioScience 39:436-446.

1992. The evolution of life histories. Oxford University Press, London, UK.

Trussell, G. C. 1996. Phenotypic plasticity in an intertidal snail: the role of a common crab predator. Evolution 50: 448-454.

Trussell, G. C., A. S. Johnson, S. G. Rudolph, and E. S. Gilfillan. 1993. Resistance to dislodgement: habitat and size-specific differences in morphology and tenacity in an intertidal snail. Marine Ecology Progress Series 100:135144.

Vermeij, G. J. 1971a. Temperature relationships of some tropical Pacific intertidal gastropods. Marine Biology 10: 308-314.

- $1971 \mathrm{~b}$. Substratum relationships of some tropical Pacific intertidal gastropods. Marine Biology 10:315320 .

. 1973. Morphological patterns in high-intertidal gastropods: Adaptive strategies and their limitations. Marine Biology 20:319-346.

Vogel, S. 1981. Life in moving fluids. Princeton University Press, Princeton, New Jersey, USA.

Watson, D. C., and T. A. Norton. 1987. The habitat and feeding preferences on Littorina obtusata (L.) and L. mar- 
iae Sacchi et Rastelli. Journal of Experimental Marine Biology and Ecology 112:61-72.

Wilkinson, L. 1989. SYSTAT: the system for statistics. SYSTAT, Evanston, Illinois, USA.

Williams, G. A. 1992. The effect of predation on the life histories of Littorina obtusata and Littorina mariae. Journal Marine Biological Association UK 72:403-416.

Williams, G. C. 1966. Adaptation and natural selection. Princeton University Press, Princeton, New Jersey, USA. 